\title{
The Performance of Undershot Water Turbine Combined With Spiral Tube Pump On Empowerment of Energy Resources Local Contiguous Small River
}

\author{
Asral, $^{a^{*}}$ Musthafa Akbar ${ }^{a}$, and Syafri ${ }^{a}$ \\ ${ }^{a)}$ Department of Mechanical Engineering, Universitas Riau, Indonesia \\ *Corresponding author: asral@lecturer.unri.ac.id
}

Paper History

Received: 13-March-2017

Received in revised form: 13-April- 2017

Accepted: 30-April-2017

\begin{abstract}
Hundreds of kilometers of irrigation canals are generally contiguous the village has not been maximally helpful as well most of damaged. Basically, in the water flow available an amount of energy could be harnessed as a renewable energy resources. Shortage of water and electricity supplies are the major issues encountered by the villager. Irrigation canals have head differences including low coupled lies in lowland areas. Picohydro electric generation, undershot-type water turbine suited for low high head applications in attemp to gain the electricity. To move the water, spiral tube pump mounted on the turbine can be installed simultaneously on generating systems. The turbine developed has an outer diameter of $2 \mathrm{~m}$ with 18 pieces of straight blade prepared from the material of aluminum. On the side of the turbine wall embeded the spiral tube pump with 5 coils was designed to operate concurrently with electrical generation. The height of water resources varied by controlling the opening of sluice gates to find out the potential. Throughout study the maximum electric voltage achievements was 125 volt. At the same time, the pump discharged the water with 9 liters per menit. These results provide sufficient supply of freshwater and electrical power for a family at contiguous area.
\end{abstract}

KEY WORDS: Undershot, Turbine, Spiral Tube Pump, Energy, Irrigation, Pico-Hydro, Combination, Electricity, Generator.

\subsection{INTRODUCTION}

The flow water in small river or irrigation provide the renewable energy but not yet widely used. In last decade, many irrigations system has been developed in Riau province in order to irrigate 250,571 hectars of lands [1]. The people who has live at around it have a problem with electrical power supply and many cases the irrigation has damaged. The damage lead to water resources has only slightly reach the lands. This condition requires the problem solving because it may affect the people economically and their survival.

The irrigation in good condition are likely to have great potential to be utilized as a power generation. In addition, based on the data from the energy ministry of human resources, throughout of Indonesia's territory available hydropower potential are about $75.5 \mathrm{GW}$ with installed capacity of $4.7 \mathrm{GW}$ [2]. Therefore the potential energy contained in the irrigation is much possible used to drive some small-scale water turbines. While in area with degredaded irrigation might be also develops the spiral tube water pump. In order to establish both water and electricity issues, the incorporation concept of water turbine with pump are proper devices to developed.

Many studies have been conducted on the utilization of energy as well as setting the energy requirements on small-scale water channel such as efficient water and energy usage for modernization irrigation [3]. Regulation and optimizing the use of water resources for consumption, irrigation and hydroelectric power plant [4]. Then the effort to improve the energy production by water power plant is also a study concern with applied the combined water cycle power generating system [5].

Some types of water turbine has been developed i.e from large scale and small scale power generation. Selection of the turbine is very dependent on the situation of the ground such as head elevation and flow. Especially for the type of breastshot and undershot turbine have suitable for low head water resources. However the turbines could suffer two efficiency losses are the 
inlet losses due to the geometry of the turbine wheel and flow friction losses the water pass through the turbine blades [6].

A study done to examines the possibility for combining the irrigation as agriculture water supply and at the same time as hydroelectric plant by reviewing various methods. It work in order to estimate the potential hydropower. Then, it has produce a simple methodology and proposed to characterize and quantify the used level of irrigation networks to produce the hydroelectric. They propose the use of hydraulic power specific and hydroelectric coefficient in order to characterize the water power potential in the irrigation network. They concluded that the methodology proposed can applied for initial analysis throughout region to network identity that might have the greatest potential for hydroelectric power production. However, specific study is essential for analysis of feasibility [7].

Water turbine has been widely used to generate electricity. Although it has represented the economical devices, efficient and sustainable technologies, but limited study that has been done today, especially for the type of waterwheel. Theoretical approach was adopted to estimate various types of power losses that occur in water turbine, to predict the mechanical power output. Theoretically results are validated with experimental data on turbine models. The characteristic curves of experimental turbine is illustrated, wherein the form of turbine efficiency and power output versus water flow rate, flow velocity and the speed of turbine wheel. The results show that high power loss theoreticallly caused by kinetic energy of flow on blade and hydraulic losses by the head, subsequently the flow through the sluice. Therefore, better design of the inlets and the geometry of the blade can improve the efficiency of the turbine [8]. Therefore, hydrological data from a potential place for development of mini hydro power plants should be included in the feasibility study of project hydropower plant development. Furthermore the data may be used for planning of irrigation land in and around the rural areas [9].

Based on previous studies, the application of small turbine on irrigation network seems as possible. Small turbine combined with spiral pump are the new study and also the study like that is limited. The new design needs to be done according to the conditions of the area. The performance of the new turbine combined with spiral pump are aims of this study.

\subsection{METHODS AND TEST EQUIPMENT}

Designing and manufacturing a set of small-scale water turbine for power generation combined with spiral water pump are the method to understand the pre-behaviour of water turbine applied on irrigation. Then performs installation and testing on local contiguous irrigation to gain the data.

\subsection{Location and Condition}

The irrigation condition like a rural is represented in Figure 1. Koto Tibun is a village located $30 \mathrm{~km}$ to west from Pekanbaru city in Riau Province of Indonesia. Here, was developed a small water dam in attempt to stem the water on a river. On the dam was divided into several sluice gates to flow into some irrigation channels.The irrigation aims to irrigate the agriculture, the fisheries and the daily necessities.
As the location for the development of a mini power plant and therefore has performed measurements on the potential energy of water. On the location was collected the data about height of water flow, flow, and area of water surface respectively are 0.76 $\mathrm{m}, 0.27 \mathrm{~m} / \mathrm{s}$ and $0.6 \mathrm{~m}^{2}$. The estimation for power generation is approximately $0.8 \mathrm{~kW}$. The height of water could be adjusted by sluice gate. According to the survey the height of water is a representation the flow rate due to the elevation difference along the irrigation canal are rather constant.
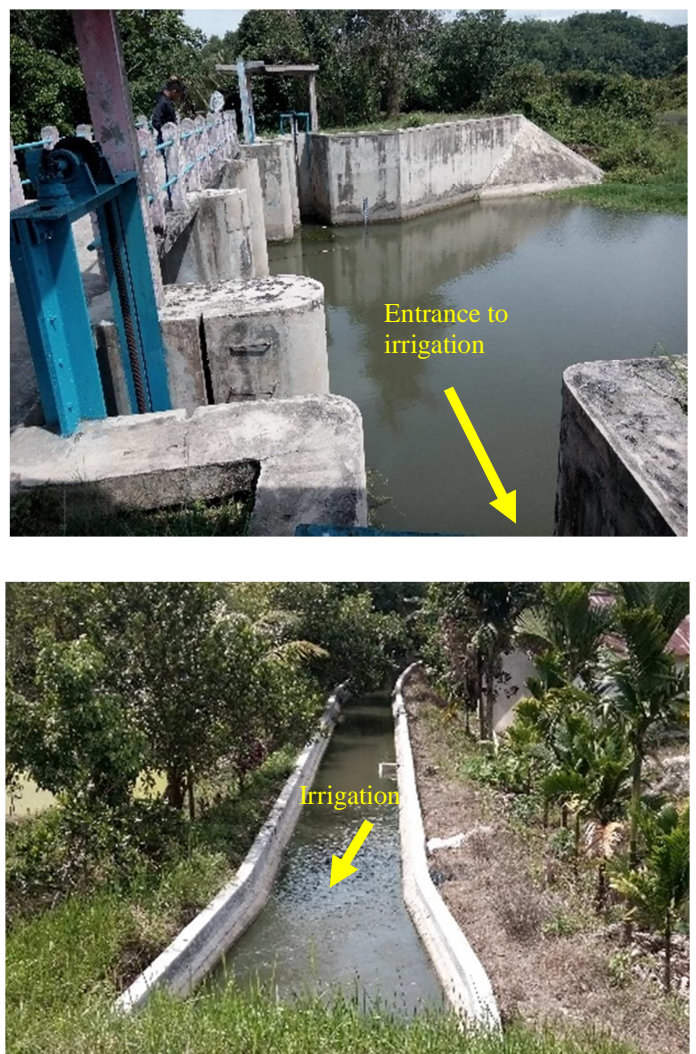

Figure 1: Description of location for application a undershot water turbine, Koto Tibun Village.

\subsection{Turbine Combination and Components}

The main component of turbine combination has arranged as seen in Figure 2. The undershot water turbine combined with spiral pump embeded in one of turbine wall. As in Figure 2 the arrangement of part respectively are inlet water funnel (1), coil tube (2), rotary water valve (3), outlet water tube (4), water wheel (5), electric generator (6), and multilevel transmission (7). The turbine fabricated from the material of aluminium and the spiral pump from polyester. The component was manufactured in workshop then assembling on irrigation canal. Furthermore, all activities such as data collection is underway at that location. For details, the size and spesification of the turbine and spiral pump are presented in Table 1. 


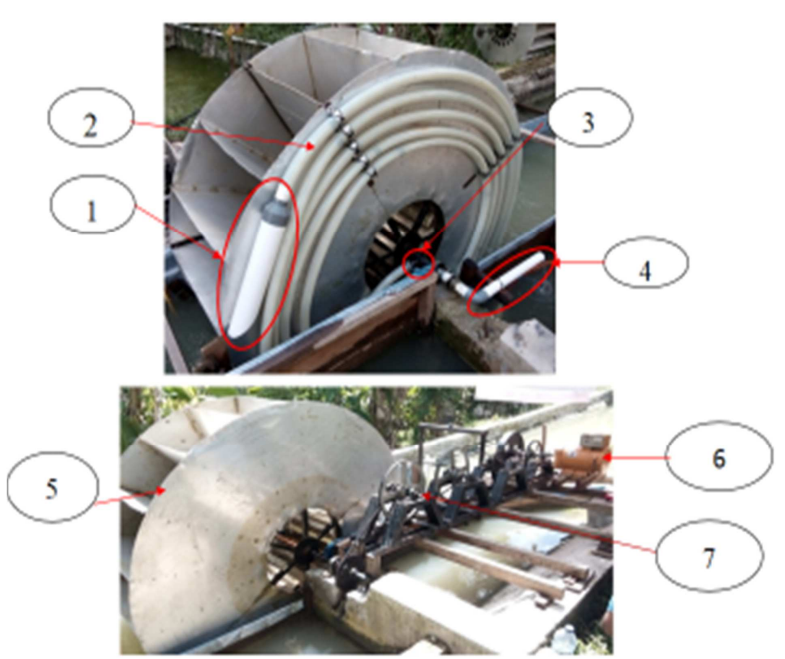

Figure 2: Parts arrangement of turbine and combination

Table 1: Size and specification of main component the turbine combination

\begin{tabular}{|l|l|}
\hline \multicolumn{1}{|c|}{ Components } & Size and Specification \\
\hline Turbine & \\
Width of turbine blade & $0.7 \mathrm{~m}$ \\
Length of turbine blade & $0.7 \mathrm{~m}$ \\
Thickness of turbine blade & $2 \mathrm{~mm}$ \\
Number of turbine blade & 18 pieces \\
Material of turbine blade & Aluminium \\
Outside diameter of turbine wheel & $2 \mathrm{~m}$ \\
Inside diameter of turbine wheel & $0.6 \mathrm{~m}$ \\
& \\
Spiral tube pump & $2 \mathrm{~m}$ \\
Outer diameter of spiral tube pump & 3 in \\
Funnel diameter of spiral tube & \\
pump & 1.5 in \\
Tube diameter of spiral tube pump & $5 \mathrm{coil}$ \\
Number of coil tube & 1.5 in \\
Diameter of outlet water tube & PVC and Polyester \\
Material of spiral tube pump &
\end{tabular}

Collecting the data of about the main parameters of the test carried out when assembling and setting throughout the turbine components were completed. Likewise the rotations were measured by tachometer and the voltages measured by voltmeter, as illustrated in Figure 3. The discharge of pump was determined by a measuring cup and stopwatch. To vary the height of water flow is intended to locate the maximum and minimum values for those parameters. Then to accomplish of its purpose the height of water flow governed by sluice gate located on the dam. Each the height of water flow be measurable with the reguler water-levelmeter.
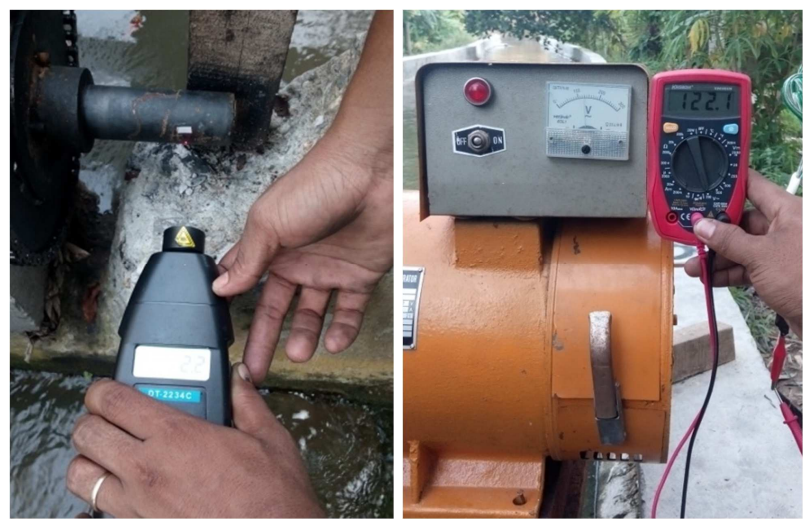

Figure 3: Rotation and voltage measurement

\subsection{RESULTS AND DISCUSSION}

Figure 4 shows the characteristics of water height at the turbine inlet to the water discharge that are pumped by spiral tube pump. The other line shows the amount of electrical voltage generated by the electric generator. As driver the spiral tube pump and the electric generator during the test are solely derived from the water wheel. both line curves shows data trends are increase as the water height increase. Increase in water height in this study could mean increase the flow rate in the irrigation canal as energy resources. Therefore, the pump can increase the flow rate at the pump inlet which necessarily would then resemble spiral down the drain. On the other hand when the turbine acts as electrical generator driver, the increase in the flow rate means increasing the mass flow rate that rotate the wheel.

The increase in mass flow rate may could increase the amount of energy available in the water resources. Other results that can be seen from this exposure are as the pump, the turbine can operate at water heights are lower than the turbine serves as an electric generator. Turbine down into off as electric generator when the water height of about $0.65 \mathrm{~m}$. Meanwhile, it act as a pump is estimated to be operating in water height of at least $0.5 \mathrm{~m}$. These data imply that in order to drive a power generation takes the flow has much greater than the spiral pump.

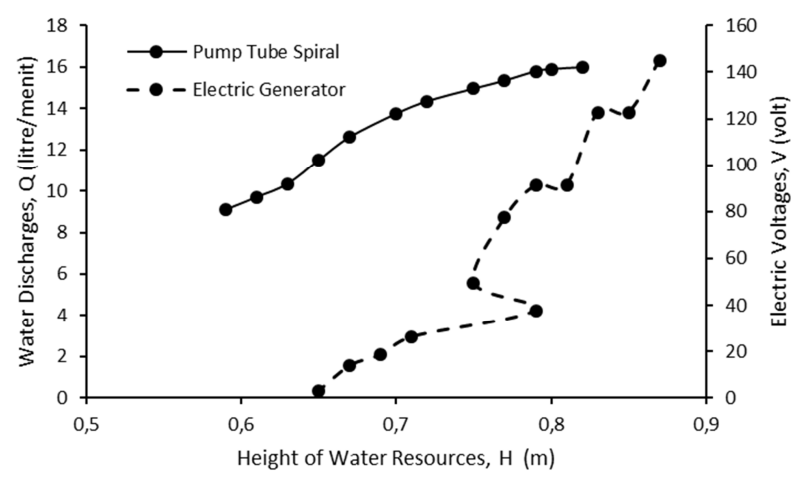

Figure 4: Characteristic of changes in height of water resources on respective pump discharge and electrical voltage 
Now, when the water flow force the blades are then produce the rotation on water wheel. As shown in Figure 5, in the individually testing has shown the different function of the water wheel seem to make a difference at the operational rotation of that machine. In order to turn the spiral pump the water wheel operates at rotation of about 2.5 to $4.5 \mathrm{rpm}$ have produces the discharge aproximately 16 liters per menit. It is equivalent to the discharge a household water pump. In prediction, it could provide the water supply of a fish pond. As the electric generation, the operational rotation of water wheel was about 0.6-2.5 rpm generate the electrical voltage maximum of about 145 volt. These results imply that the spiral pump requires less energy source than an electric generator.

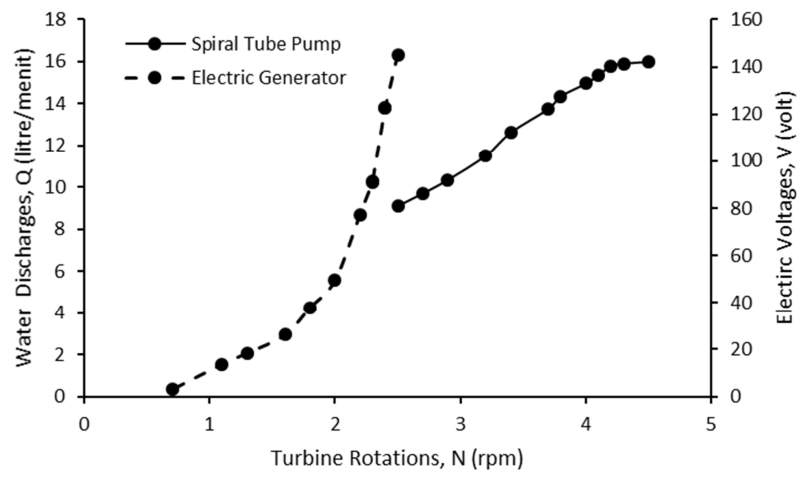

Figure 5: Characteristic of changes in turbine rotations on respective pump discharge and electrical voltage

As combination, the turbine uses have led to increase the needs of water flow rate as energy resources in irrigation system. As the spiral pump and the electric generator consecutively have produces a decrease in discharge and voltage. As shown in Figure 6 , seem to a small percentage of water energy absorbed in order to drive the spiral pump but remaining greater for the electric generator. Due to small flow, the energy available in water resources are limited, causing decrease the discharge and voltage achievement. The maximum water discharge that can be transferred by the pump is reduced by about 6 liters per minute. However, it was balanced by a decrease in maximum voltage output of about 20 volts. Fortunately, as the height of water increases conduce discharge and voltage increases.

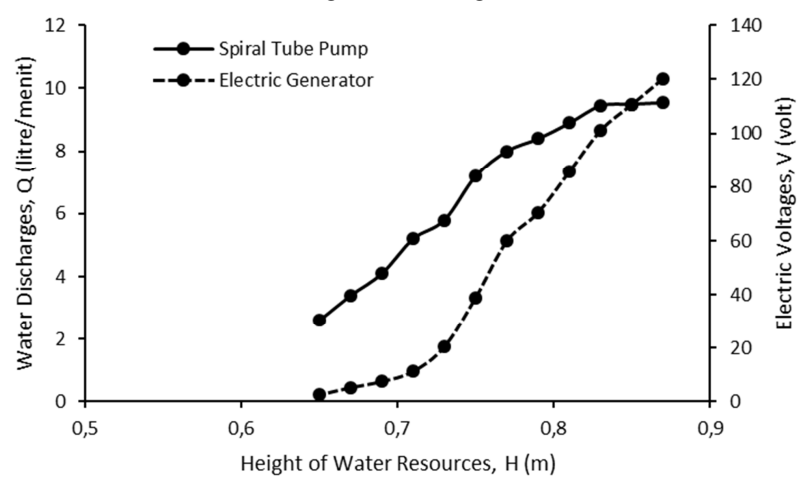

Figure 6: Characteristic of changes in height of water resources on combination pump tube spiral and electric generator
The rotation could be a visualization the energy contained in water flow at the irrigation canal. In combination turbine functions, the rotation increment has caused increase in pump discharge and voltage generation. As shown in Figure 7, it can be seen that the effects of turbine rotation changes on both parameters are differently slope. This result is due to the water resources requirement to drive the spiral pump and electric generator are significant difference.

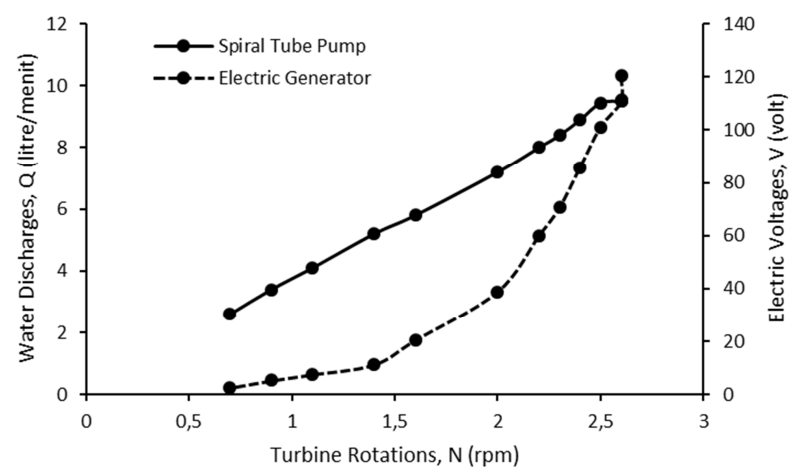

Figure 7: Characteristic of changes in turbine rotations on combination pump tube spiral and electric generator.

\subsection{CONCLUSION}

This study reveals the performance of undershot water turbine applied particularly on irrigation canal based on local potency. The conclusion can be drawn are:

1. To drive the turbine with spiral tube pump and electric generator simultaneously were required the height of water flow are about $0.6 \mathrm{~m}$ minimum and $0.9 \mathrm{~m}$ maximum.

2. The generator could produce approximately 450 Watt electrical power, is quite to fullfill the needs of a household.

3. The pump have discharge 14 litres per menit water. This achievement is quite to maintaine the water requirement for a fish pond.

4. The undershot water turbine has convenient for the application on small river or irrigation contigously village.

\section{ACKNOWLEDGMENTS}

The authors would like to convey deep gratitude to Lembaga Penelitian dan Pengabdian Kepada Masyarakat Universitas Riau (LPPM-UR) which has provide financial support to completion of this research.

\section{REFERENCE}

1. http://bappenas.go.id/files/7813/5022/6072/bag-04-89-90cek_200901300740.

2. BPPT, (2012).”Outlook Energy Indonesia”. Energy Ministry of Human Resources Republic of Indonesia.

3. Tarjuelo, José M., Rodriguez-Diaz, Juan A., Abadía, 
Ricardo, Camacho, Emilio, Rocamora, Carmen and Moreno, Miguel A., (2015). Efficient Water and Energy Use in Irrigation Modernization: Lessons from Spanish Case Studies, Agriculture Water Management, Int. Journal, 162, 67-77

4. Wu, Yiping, and Chen, Ji , (2013). Estimating irrigation water demand using an improved method and optimizing reservoir operation for water supply and hydropower generation: A case study of the Xinfengjiang reservoir in southern China, Agriculture Water Management, Int. Journal, 116, 110-121

5. Liu, Yue, and Packey, Daniel J., 2014. "Combined-Cycle Hydropower Systems - The Potential of Applying Hydrokinetic Turbines in The Tailwaters of Existing Conventional Hydropower Stations", Renewable Energy, Int. Journal, 66, 228-231.

6. Williamson, S.J, Stark, B.H, and Booker, J.D. 2014. "Low Head Pico Hydro Turbine Selection Using a Multi-Criteria Analysis". Renewable Energy, Int. Journal, 61, 43-50.

7. Butera, Ilaria and Balestra, Roberto, 2015." Estimation of the Hydropower Potential of Irrigation Networks,

Renewable and Sustainable Energy Reviews, Int.Journal. 48, 140-151

8. Quaranta, Emanuele, and Revelli, Roberto, 2015, "Performance Characteristics, Power Losses and Mechanical Power Estimation for a Breastshot Water Wheel', Energy, Int.Journal, 87, 315-325.

9. Adhau, S.P., Moharil, R.M. and Adhau, P.G. ,2012, "MiniHydro Power Generation on Existing Irrigation Projects: Case Study of Indian Sites", Renewable and Sustainable Energy Reviews, Int Journal, 16, 4785-4795. 